\begin{tabular}{|c|c|}
\hline \multirow{3}{*}{ 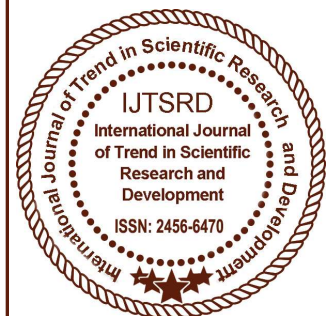 } & $\begin{array}{l}\text { International Journal of Trend in Scientific } \\
\text { Research and Development (IJTSRD) }\end{array}$ \\
\hline & International Open Access Journal \\
\hline & ISSN No: 2456 - 6470 | www.ijtsrd.com | Volume - 2 | Issue - 1 \\
\hline
\end{tabular}

\title{
Improving the Performance of PEM Fuel Cell by Varying the Number of Flow Channels
}

\author{
M. Saravanan \\ Assistant Professor, Department of Mechanical \\ Engineering, DMI College of Engineering, \\ Chennai, Tamilnadu, India
}

\author{
R. Girimurugan \\ Assistant Professor, Department of Mechanical \\ Engineering, Nandha College of Technology, \\ Erode, Tamilnadu, India
}

\begin{abstract}
A fuel cell is a device that converts chemical energy into electrical energy, water, and heat through electrochemical reactions. The water formation cause major problem and it affects performance of fuel cell. In PEM fuel cell excess and least amount of water level may reduces the performance and the efficiency of the fuel cell. The performance of PEM fuel cell mainly depends on flow parameters and design parameters. In this project, the number of pass of serpentine type flow channel was varied and their performances were calculated. The complete model of PEM fuel cell with single, two \& three pass serpentine type flow channels were modeled using SOLID WORKS \& AUTOCAD software packages, the surface meshing was done using ANSA software, volume meshing was done using TGRID software and analysis was done using ANSYS FLUENT 13.0 software. From the analysis, it was found that the three pass serpentine type flow channel gave better performance, when compared to single pass and two pass flow channels.
\end{abstract}

Keywords: PEM Fuel Cell, Performance, Number of Flow Channels.

\section{Introduction}

\subsection{PEM Fuel Cells}

In proton-exchange membrane fuel cells (PEMFCs), the polymeric proton exchange membrane serves as a solid electrolyte. The membrane's conductivity comes about because in the presence of water, it swells, a process leading to dissociation of the acidic functional groups and formation of protons free to move about throughout the membrane. The electrochemical reactions occurring at the electrodes of PEMFCs as well as the overall current producing reaction are the same as in the hydrogen-oxygen fuel cells with liquid acidic electrolyte. The most common channel design on a bipolar plate is a serpentine design, as shown in Figure.1. Characterization of the fluid dynamics in the serpentine gas flow channels is essential to understanding and improving mixing. So far, the highly reactive environment of a fuel Cell has been a major challenge to detailed in-situ measurements during operation, and though significant progress has been made in computational modeling, the complexity of the phenomena has required a number of simplifying assumptions, and in particular the flow in these models is assumed steady and laminar.

\subsection{Design of flow channels}

There are many varieties of flow field layouts for bipolar plates that have been developed and patented, but there is little information in the open literature regarding the design procedure or methodology for the channel length and cross-sectional dimensions as well as the pressure drops for flow in the channels. In this section, a general procedure for the flow channel design will be described by using the fundamental concepts of flow through rectangular ducts or pipes for a given active area of PEM fuel cells as an illustrative example. The operating conditions of the PEM fuel cells are taken into account for the design 
process. Proper water management in polymer electrolyte membrane (PEM) fuel cells is critical to achieve the potential of PEM fuel cells. Membrane electrolyte requires full hydration in order to function as proton conductor, often achieved by fully humidifying the anode and cathode reactant gas streams. On the other hand, water is also produced in the cell due to electrochemical reaction. The combined effect is that liquid water forms in the cell structure and water flooding deteriorates the cell performance significantly. Sample flow channels have been designed, manufactured and tested for five different cell sizes of 50, 100, 200, 300 and $441 \mathrm{~cm}^{2}$. Similar cell performance has been measured for these five significantly different cell sizes, indicating that scaling of the PEM fuel cells is possible if liquid water flooding or membrane dehydration can be avoided during the cell operation. It is observed that no liquid water flows out of the cell at the anode and cathode channel exits for the present designed cells during the performance tests, and virtually no liquid water content in the cell structure has been measured by the neutron imaging technique. The literature survey was carried out in order list out to explore the numerical analysis performed in the area of the PEM fuel cell. Emphasis was mainly laid upon the area of boundary and initial condition while analysis or the usage of the computational fluid dynamics tools and the way by which the analysis were referred.

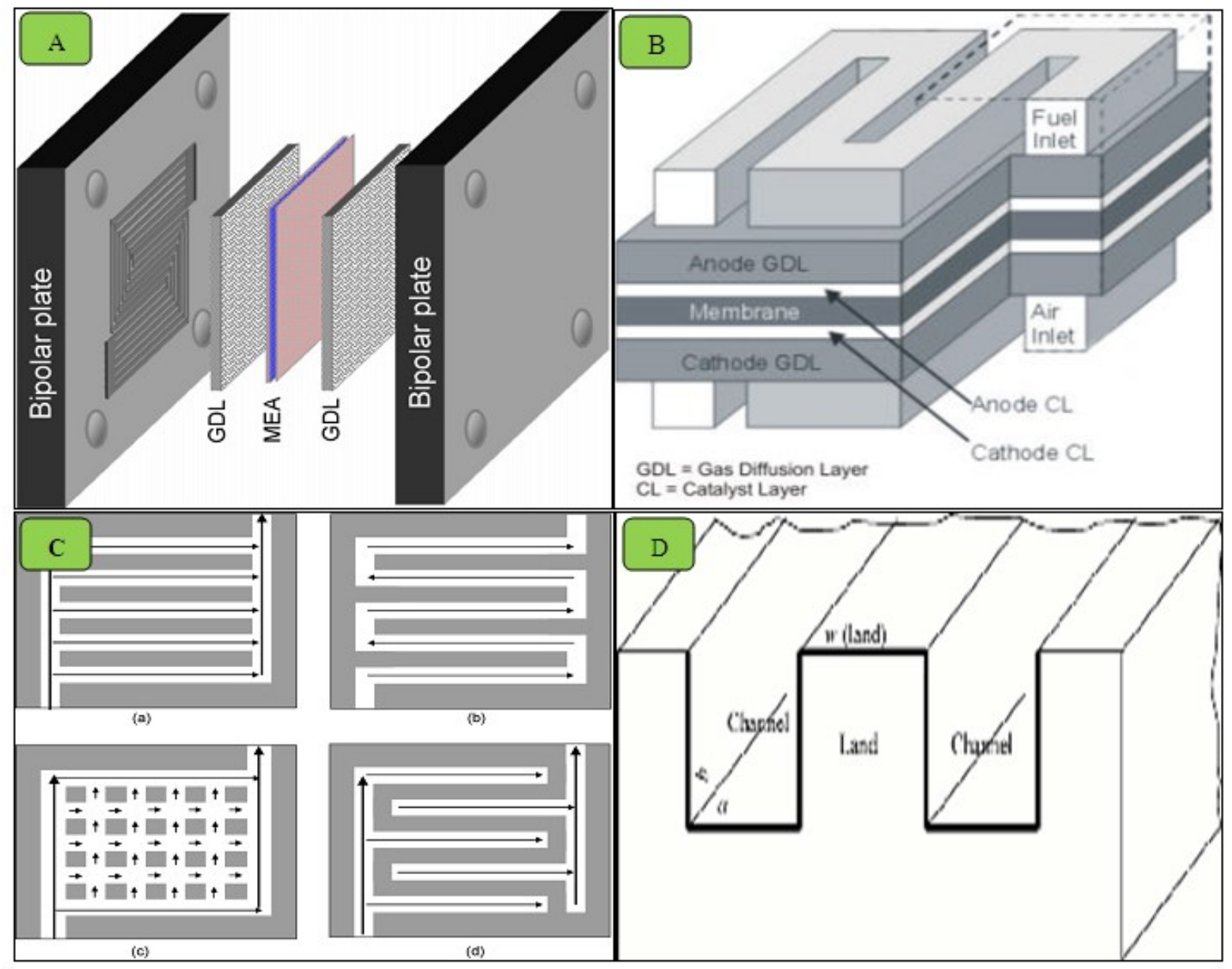

Fig 1: (A) Bipolar Plate (B) PEM Fuel Cell (C) Typical flow fields of PEFCs. (a) Parallel flow field; (b) Serpentine flow field; (c). Pin flow field; (d) Interdigitated flow field (D) Flow channel design.

The experimental diagnosis and measurement of water management is discussed in this paper. The electro-osmotic drag can also lead to dehydrated condition at the anode. At high current densities the water replenishment by back-diffusion is not sufficient to keep the anode side of the membrane hydrated. Over-humidified reactant gases and liquid water injection also lead to flooding. At low current densities, if the relative humidity is not as high as at the cathode, water back-diffusion through the GDL to the anode will surpass the electro-osmotic drag effect leading to the increase of water content in the anode, especially at the exit [1]. The channel cross-sectional shape can influence both the pressure drop and the 
flow cross over. A numerical study of the pressure distribution and flow cross-over length through the gas diffusion layer in PEM fuel cell flow plates using a serpentine channel system has therefore been undertaken for the case where the channel has trapezoidal cross sectional shape, the trapezoidal channel cross sectional shape having the potential to reduce the pressure drop and to augment the flow cross over [2]. In this work, the liquid water breakthrough dynamics, characterized by the capillary pressure and water saturation, across GDLs with and without a micro porous layer (MPL) are studied in an ex-situ setup which closely simulates a real fuel cell configuration and operating conditions. The results reveal that recurrent breakthroughs are observed for all of the GDL samples tested, indicating the presence of an intermittent water drainage mechanism in the GDL. This is accounted for by the breakdown and redevelopment of the continuous water paths during water drainage as demonstrated by Haines jumps.

For GDL samples without MPL, a dynamic change of breakthrough locations is observed, which originates from the rearrangement of the water configuration in the GDL following the drainage. For GDL samples with MPL, no dynamic change of breakthrough location can be found and the water saturation is significantly lower than the samples without MPL. The most important result is that GDL without MPL promotes film flow and shifts the slug-to-film flow transition to lower air flow rates, compared with the case of GDL with MPL. This is closely related to the larger number of water breakthrough locations through GDL without MPL, which promotes the formation of water film [3]. Envisaging the minichannels as structured and ordered porous media, we develop a continuum model of two-phase channel flow based on two-phase Darcy's law and the $M 2$ formalism, which allow estimate of the parameters key to fuel cell operation such as overall pressure drop and liquid saturation profiles along the axial flow direction. Analytical solutions of liquid water saturation and species concentrations along the channel are derived to explore the dependences of these physical variables vital to cell performance on operating parameters such as flow stoichiometric ratio and relative humility. Three issues critical to optimizing channel design and mitigating channel flooding in PEM fuel cells are fully discussed: liquid water buildup towards the fuel cell outlet, saturation spike in the vicinity of flow cross-sectional heterogeneity, and two-phase pressure drop [4]. The model is coupled with a nonlinear constrained optimization algorithm to determine an optimum design of the fuel cell with respect to the operation and the geometrical parameters of cathode such as the air inlet pressure, the cathode thickness and length and the width of shoulders in the interdigitated air distributor. The results of the optimization analysis show that higher current densities at a constant cell voltage are obtained as the inlet air pressure and the fraction of the cathode length associated with a shoulder of the interdigitated air distributor are increased, and as the cathode thickness and the length of the cathode per one interdigitated gas distributor shoulder are decreased. The statistical sensitivity analysis results, on the other hand, show that the equilibrium cathode/membrane potential difference has the largest effect on the predicted polarization curve of the fuel cell [5]. Excessive air flow rates and serpentine channel designs are used to mitigate flooding at the cost of system efficiency. In this paper, we present an active water management system that decouples water removal from oxidant delivery. The system uses a porous carbon flow field plate as an integrated wick that can passively redistribute water within the fuel cell. The system also employs an external electro-osmotic _EO_ pump that actively removes excess water from the channels and gas diffusion layer.

Experimental and modeling results show that simple passive water transport through the porous carbon alone can prevent flooding at certain operating conditions and flow field dimensions. However, active water management with EO pumping facilitates robust operation with a high volumetric power density across all operating conditions [6]. The consumption of gases in the flow field channels, coupled to the electric potential and water content in the polymer membrane, is modeled in a two-dimensional slice from inlet to outlet and through the membrane. Both co- and counter-flowing air and fuel streams are considered, with attention paid to sensitivity of alongthe-channel current density to inlet humidifies, gas stream composition, and fuel and oxygen stoichiometries. The parameters describing the no equilibrium kinetics of the membrane/catalyst interface are found to be fundamental to accurate fuel cell modeling. A new parameter which models no equilibrium membrane water uptake rates is introduced. Four parameters, the exchange current, a membrane water transfer coefficient, an effective oxygen diffusivity, and an average membrane 
resistance, are fit to a subset of data and then held constant in subsequent runs which compare polarization curves, current density and membrane hydration distributions, water transfer, and stoichiometric sensitivity to the balance of the experimental data [7].

\section{Methodology}

The methodology of this study is shown in figure.2.

\section{Data Collection}

Before going for computational modeling the data required for the serpentine rectangular cross-section PEM model is collected from PSG institute of advanced studies where the experimental analysis of PEM models were done. At first we are doing numerical analysis of PEM models being used in PSG for experiments. The data's collected include,

- Dimensions for serpentine $1 \times 1$

- Operating conditions

- Experimental results for serpentine $1 \times 1$ at 1 bar pressure

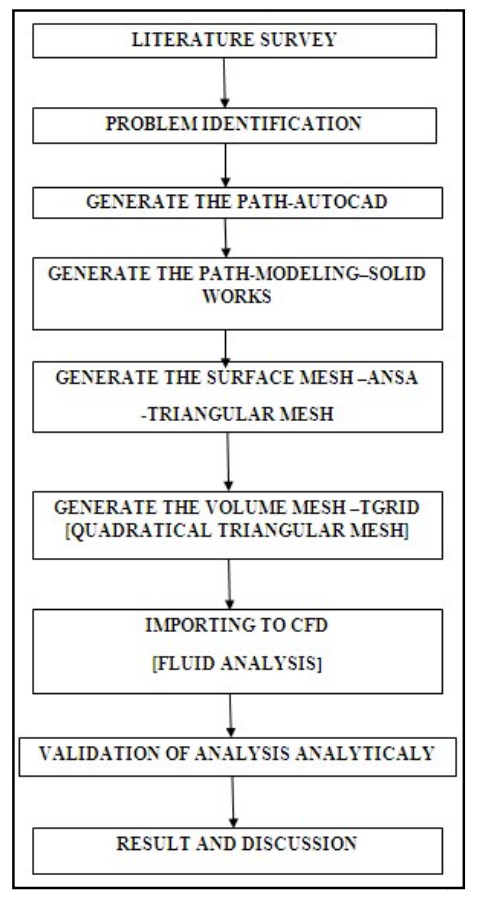

Fig 2: Methodology

\subsection{Dimensions for Serpentine 1x1 Model}

The details of parameters are shown above in table 6.1.The data's regarding design parameters like width of the flow channel, GDL thickness etc. are collected from the fuel cell laboratory in PSG Institute of Advanced Studies.

\subsection{Experimental Results}

The current density generated at 1 bar pressure and 500c for varying electric potential from 0.2 to 1 volt. For these conditions the experimental analysis is carried out for serpentine $1 \times 1$ rectangular crosssection PEM fuel cell model. Obtained experimental result for the serpentine $1 \times 1$ model from the PSG IAS are tabulated below. Polarization curve for the experimental results is drawn by plotting values for current density and electric potential. Fuel Cell with rectangular serpentine channel is designed as per the model used for experimentation using SOLID WORKS 2013. The dimension of the channel width and depth are $1 \mathrm{~mm}$ and the rib thickness is $1 \mathrm{~mm}$ is shown in Fig.6.2. Similar to this we have also designed semicircular and triangular flow channel with same channel width of $1 \mathrm{~mm}$. 


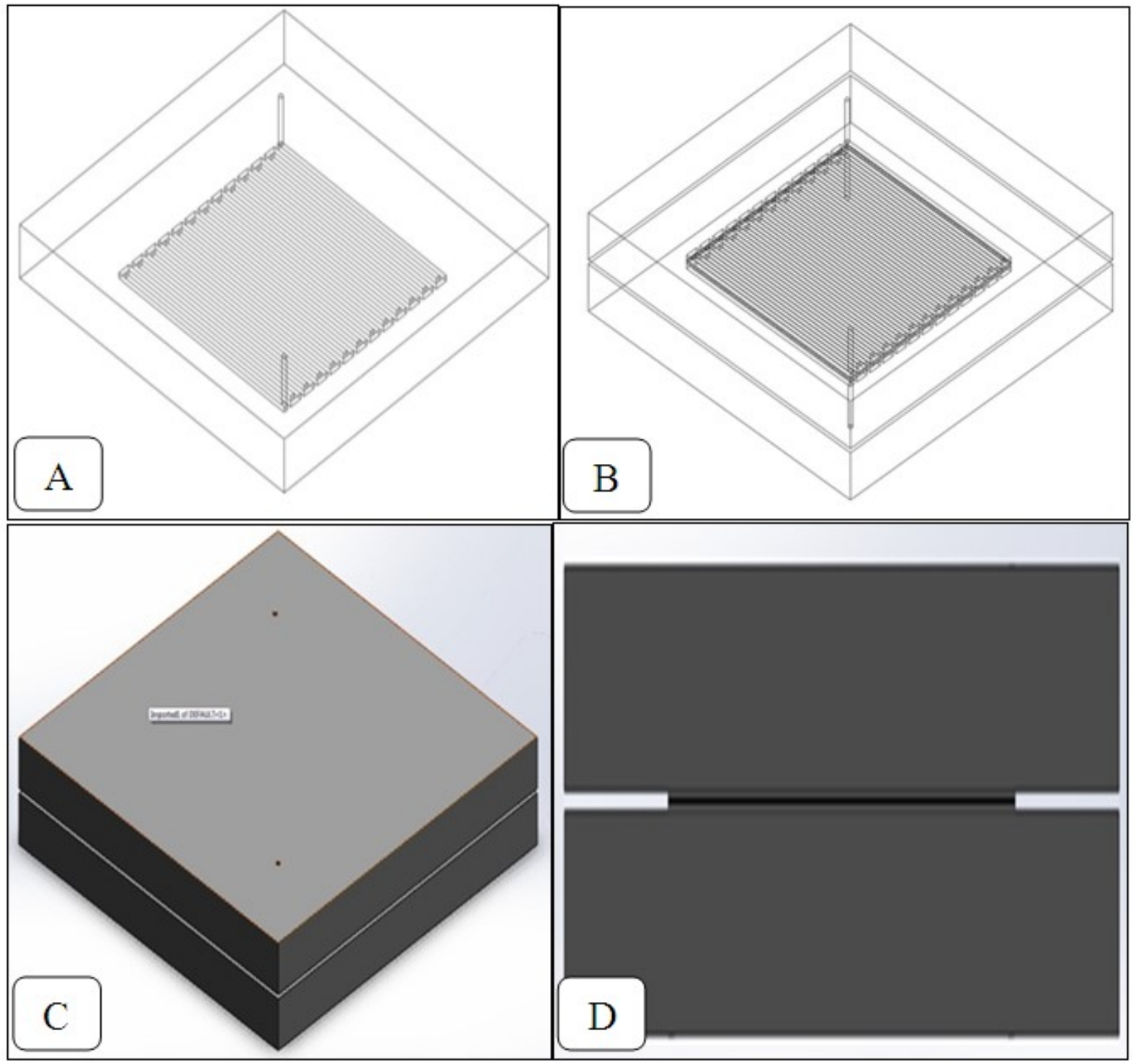

Fig.3. (A) Channel Model (B) Isometric View- PEM Fuel Assembly (C) Solid works 2012- PEM fuel model (D) Full Assembly Front View. 
International Journal of Trend in Scientific Research and Development (IJTSRD) ISSN: 2456-6470

\begin{tabular}{|c|c|c|c|c|}
\hline${ }^{1.2}$ & & $\begin{array}{l}\mathbf{V}_{\text {cathod }} \\
\text { e (V) }\end{array}$ & $\begin{array}{c}I_{\text {anode }} \\
\left(\mathrm{A} / \mathrm{cm}^{2}\right)\end{array}$ & $\begin{array}{c}I_{\text {cathode }} \\
\left(\mathrm{A} / \mathrm{cm}^{2}\right)\end{array}$ \\
\hline$\hat{\Sigma}_{08}$. & & 0.2 & 0.2265 & 0.2265 \\
\hline & & 0.3 & 0.2171 & 0.2218 \\
\hline$\overbrace{2}^{8} 0.6$ & & 0.4 & 0.225 & 0.278 \\
\hline & - linear Syeres1) & 0.5 & 0.218 & 0.218 \\
\hline \pm & & 0.6 & 0.1765 & 0.1765 \\
\hline 6.2 . & & 0.7 & 0.1125 & 0.1125 \\
\hline 0 & & 0.8 & 0.048 & 0.048 \\
\hline 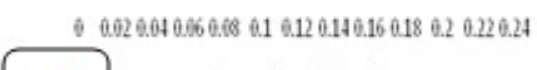 & & 0.9 & 0.006 & 0.006 \\
\hline 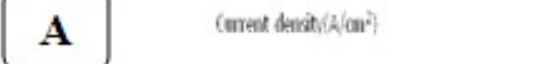 & & B 1 & 0.001 & 0.001 \\
\hline
\end{tabular}

Fig 4: (A) Polarization curve (B) Experimental results.

\section{RESULTS AND DISCUSSIIONS}

\subsection{Single Pass Serpentine Type Channel}


International Journal of Trend in Scientific Research and Development (IJTSRD) ISSN: 2456-6470

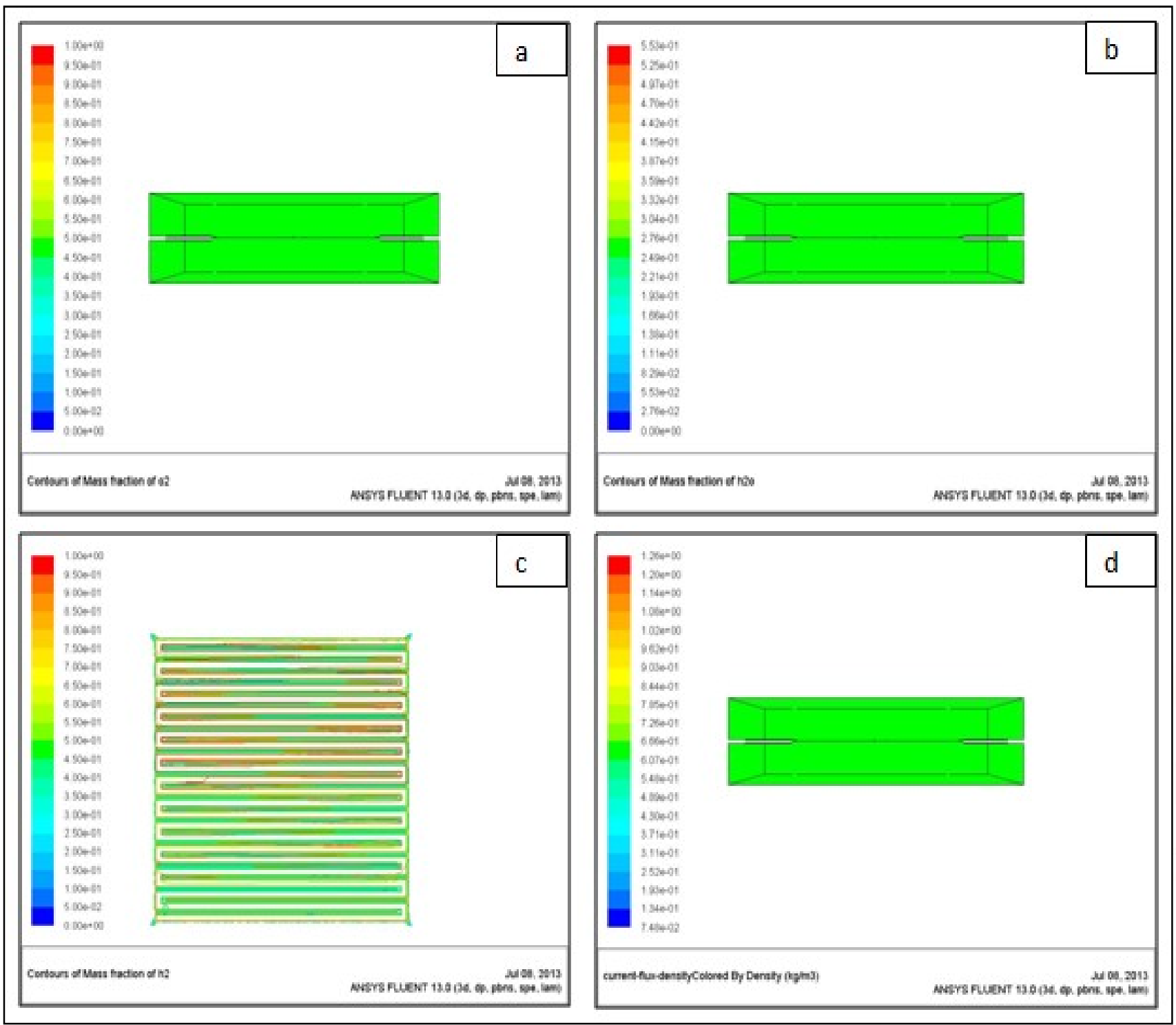

Fig 5: (a) $\mathrm{O}_{2}$ Mass fraction (b) $\mathrm{H}_{2} \mathrm{O}$ Mass fraction (c) $\mathrm{H}_{2}$ Mass fraction (d) Current Density for 0.2 cell voltage for single pass serpentine flow. 


\subsection{Two Pass Serpentine Type Channel}

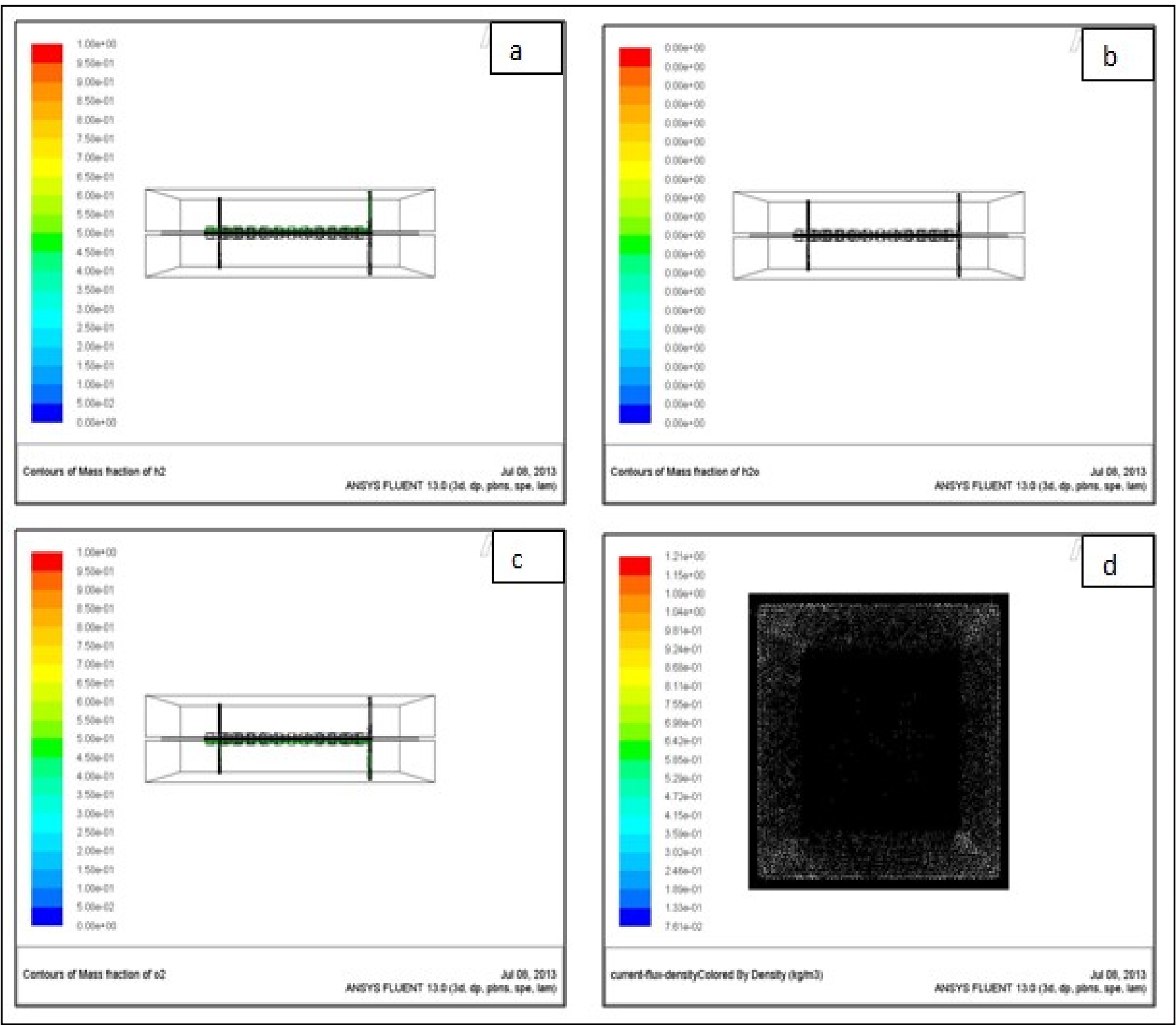

Fig 6: (a) $\mathrm{O}_{2}$ Mass fraction (b) $\mathrm{H}_{2} \mathrm{O}$ Mass fraction (c) $\mathrm{H}_{2}$ Mass fraction (d) Current Density for 0.2 cell voltage for two pass serpentine flow. 


\subsection{Three Pass Serpentine Type Channel}

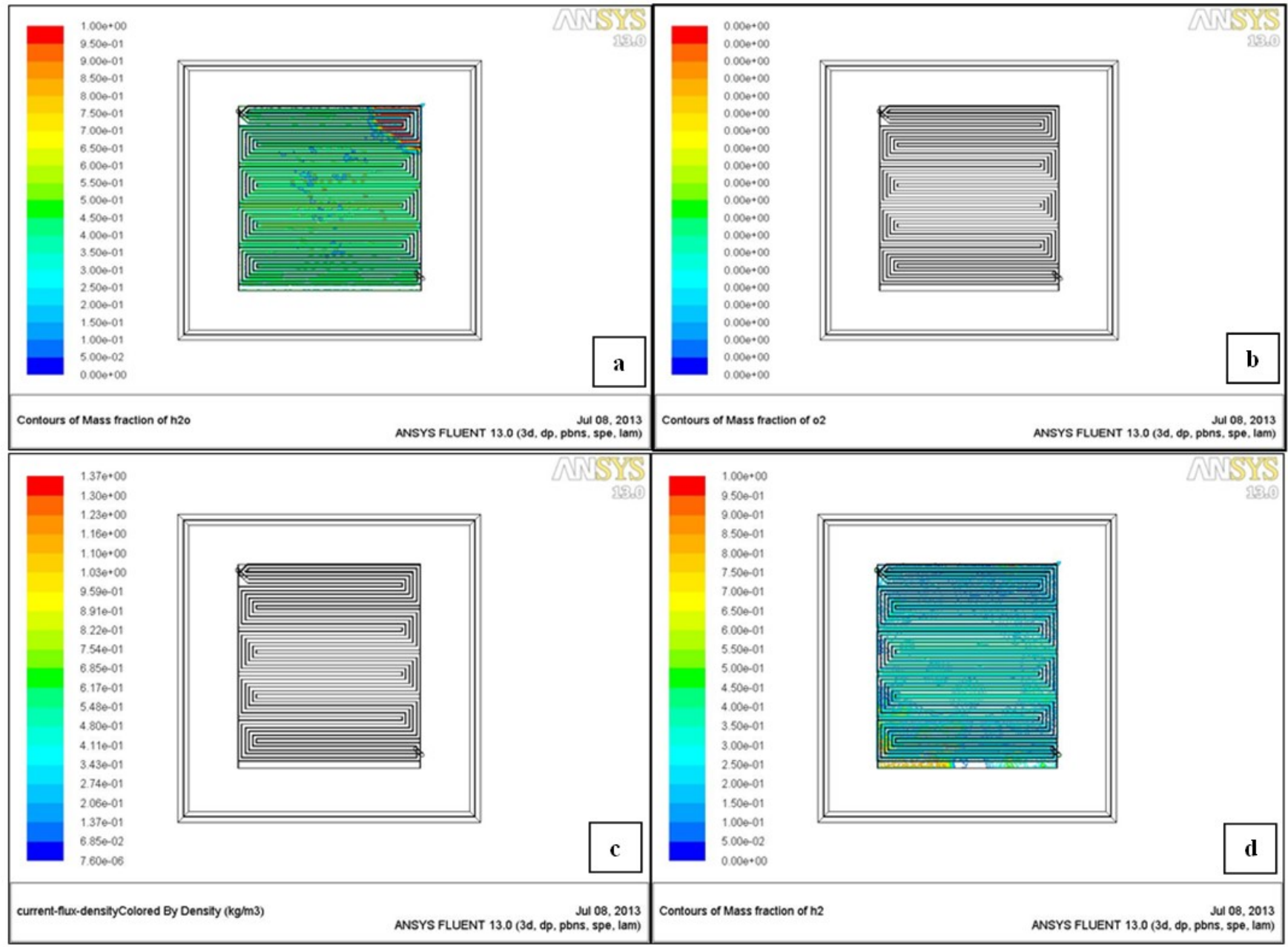

Fig 7: (a) $\mathrm{H}_{2} \mathrm{O}$ Mass fraction (b) $\mathrm{O}_{2}$ Mass fraction (c) Current Density for 0.2 cell voltage (d) $\mathrm{H}_{2}$ Mass fraction for two pass serpentine flow.

\section{Conclusion and Future Work}

The various pass flow channel were considered for the performance of PEM fuel cell. Various flow parameters, operating temperature, operating pressure, and direction of flow of reactant gases were same for all flow channels. While considering serpentine three pass flow channel, it is better in terms of current output compared to single flow and two flow serpentine type channels. These above results are given based on numerical analysis done in fluent software. However, these results are to be verified by conducting experiments in the actual set ups.

Fuel cells can play a significant role in the future energy market if the current targets of increased performance with least water formation in cathode side of the fuel cell achieved. In future, various shapes of the flow channels, various channel dimensions may also be considered for the analysis.

\section{REFERENCES}

1. Advanced Materials \& Composites News (2001) January 2, v23 i507.

2. Borgwardt, Robert H., (2001) "Platinum, fuel cells, and future US road transport,"

Transportation Research Part D 6 199-207.

3. Cannon, James, (1988) "Hydrogen: America's Road to Sustainable Transportation".

4. Gottesfield, Shimshon, (2000), "The Polymer Electrolyte Fuel Cell: Material Issues in a Hydrogen Fueled Power Source.

5. Hackney, Jeremy and de Neufville, Richard, (2001) "Life cycle model of alternative fuel vehicles: emissions, energy and cost trade-offs" Transportation Research. Part A, General. 
6. Hoffman, Peter, (2001) Tomorrow's Energy, "Hydrogen, Fuel Cells and the Prospects for a Cleaner Planet" Peter Hoffman, The MIT Press.

7. Lucks, Raimer and Moller, Christian, (1999) "Seminar: Fuel Cells" www.tf.unikiel.de/matwis/matsci/project/fuelcells.

8. Miller, G.Tyler, Jr., (2002) Living in the Environment, $12^{\text {th }}$ edition Thomson Learning, Inc.

9. Ohi, J., (2000) "Blueprint for Hydrogen Fuel Infrastructure Development," National Renewable Energy Lab.

10. Steele, B.C.H., March 1, 2001 "Material Science and Engineering: The enabling technology for the commercialization of fuel cell systems," Journal of materials science, Vol. 36, Issue 5, pp. 1053-68.

11. St. Pierre, Jean and Wilkinson, David P., (2001) "Fuel Cells: a New, Efficient and Cleaner Power Source" American Institute of Chemical Engineers, Vol. 47, No.7, pp. 1482-1486.

12. Thomas, Sharon and Zalbowitz, Marcia, (2000) "Fuel Cells, Green Power," Los Alamos National Library www.education.lanl.gov/resources/fuel cells/fuel cells.pdf. 